\title{
What is the ideal conduit or technique for reconstruction of the right ventricular outflow tract?
}

\author{
Aditya K. Kaza, MD
}

From the Department of Cardiac Surgery, Boston Children's Hospital, Boston, Mass.

Disclosures: Author has nothing to disclose with regard to commercial support.

Received for publication Jan 9, 2018; accepted for publication Jan 12, 2018; available ahead of print Feb 14, 2018.

Address for reprints: Aditya K. Kaza, MD, Department of Cardiac Surgery, Boston Children's Hospital and Harvard Medical School, 300 Longwood Ave, Bader 273, Boston, MA 02115 (E-mail: aditya.kaza@cardio. chboston.org).

J Thorac Cardiovasc Surg 2018;155:2080-1

$0022-5223 / \$ 36.00$

Copyright (C) 2018 by The American Association for Thoracic Surgery

https://doi.org/10.1016/j.jtcvs.2018.01.018

This single institution retrospective study ${ }^{1}$ examined the outcomes of right ventricular outflow tract (RVOT) reconstructions in children aged less than 2 years. The control group had valved homograft reconstruction, and the comparison group had a polytetrafluoroethylene (PTFE) conduit with a PTFE bicuspid valve (and a trifoliate valve more recently). There were no differences in conduit durability between the 2 groups, and they had overall similar outcomes and postoperative hospital length of stays. The main determinant for explanting these conduits was somatic growth of the patient and development of stenosis at the junction with the branch pulmonary arteries. This prompted the authors ${ }^{1}$ to hypothesize that there may be durability benefit in oversizing the conduit at the time of implantation if possible. The authors point out the advantages of the PTFE composite graft, and these include immediate access, lower cost, and lack of allogeneic sensitization.

However, the necessity for repeat surgery for conduit replacement in these patients remains. At Boston Children's Hospital, we have partially ameliorated this problem by using a Dacron tube with a stented valve implanted inside the tube graft and using this composite for RVOT reconstruction. Our general policy is to not oversize the stented valve by more than $+2 z$ score. An advantage of this modification is its amenability to placement of a percutaneous stent and a balloon-expandable valve inside the composite conduit. The primary mode of failure continues to be conduit stenosis. The ideal conduit would be one that can potentially "grow" or keep up with the child's somatic growth or, alternately, avoiding a conduit during RVOT reconstruction. This frequent need for conduit changes should lead us to investigate alternate ways of reconstructing the RVOT. Are there ways in which we can

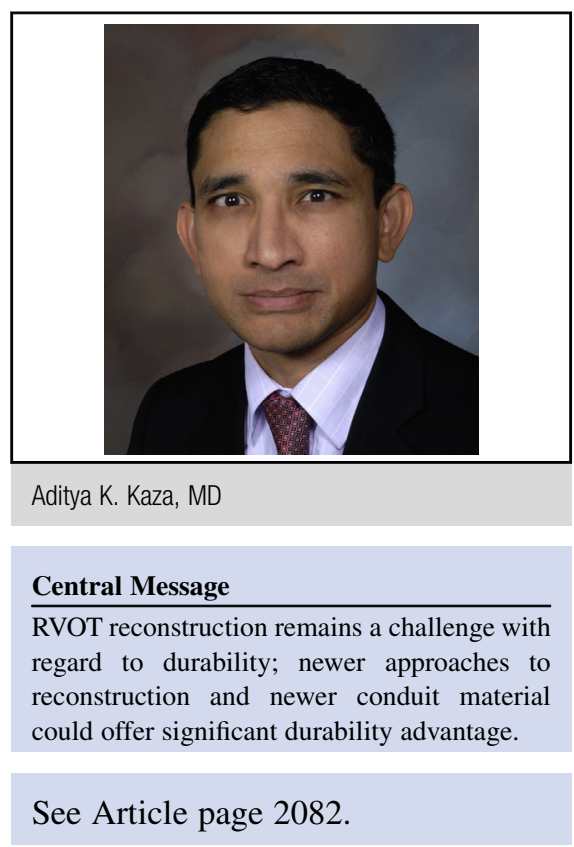

reconstruct the RVOT without using conduits? We previously showed that in patients with tetralogy, using a transannular reconstruction was more durable than a conduit. $^{2}$ Likewise, in certain patients (those with Truncus or tetralogy) the anatomy may be amenable to RVOT reconstruction without a conduit, and this is something that should be considered in these patients. Newer technology with regard to conduits that can be populated by native mesenchymal cells and potentially grow with the patient ${ }^{3}$ would be promising in these patients and could be incredibly helpful in avoiding multiple reoperations. Finally, once we solve the issue with conduit stenosis, the issue of needing a durable valve is going to come up. We have partially solved this problem with the newer balloonexpandable valves that have been noted to have excellent durability in the pulmonary position and can help prolong the duration between reoperations. RVOT reconstruction remains a challenge with regard to durability. Newer approaches to reconstruction or newer conduit material could offer significant durability advantage for this procedure. 


\section{References}

1. Mercer CW, West SC, Sharma MS, Yoshida M, Morell VO. Polytetrafluoroethylene conduits versus homografts for right ventricular outflow tract reconstruction in infants and young children: An institutional experience. J Thorac Cardiovasc Surg. 2018;155:2082-91.e1.

2. Kaza AK, Lim HG, Dibardino DJ, Bautista-Hernandez V, Robinson J, Allan C, et al Long-term results of right ventricular outflow tract reconstruction in neonatal cardiac surgery: options and outcomes. J Thorac Cardiovasc Surg. 2009;138:911-6.

3. Soliman OI, Miyazaki Y, Abdelghani M, Brugmans M, Witsenburg M, Onuma Y, et al. Midterm performance of a novel restorative pulmonary valved conduit: preclinical results. EuroIntervention. 2017;13:e1418-27. 